Available online on 15.05.2020 at jddtonline.info
Open Access to Pharmaceutical and Medical Research
unrestricted non-commercial use, provided the original work is properly cited

Open Access

Research Article

\title{
Humoral response of broilers to live Newcastle Disease virus vaccines manufactured by different companies
}

\author{
Muhammad Danish Mehmood1*, Aamra Hashim², Huma Anwar ul-haq 1, Muhammad Ismail1, Faisal Amin³, \\ Sajjad Hussain" \\ 1. Ottoman Pharma (Immuno Division), Raiwind Road Lahore-Pakistan \\ 2. Institute of Molecular Biology and Biotechnology, University of Lahore-Pakistan \\ 3. Grandparent Diagnostic Laboratory, Lahore, Pakistan \\ 4. Veterinary Research Institute, Lahore, Pakistan
}

\begin{abstract}
Increased incidence and severity of fatal Newcastle Disease Virus (NDV) in commercial and domestic poultry has been reported from across Pakistan. The present study was carried out to evaluate the efficacy of various live NDV vaccines (Gallivac, Intervet and Ceva) by adapting different vaccination schemes in broilers. Antigenic count of each vaccine and its generated antibody were determined by Haeamagglutination and Haemagglutination inhibition tests respectively. Two different NDV vaccination schemes were tested in such a way that one group had received three vaccines in different time periods whereas, the other after priming at 0 day, was followed by a single booster dose. For this purpose, healthy broilers were divided into four groups A, B, C, and D. On zero day of vaccination, there was no detectable a nti NDV-HI titer for all vaccines (Gallivac $=2$, Intervet $=2 \&$ Ceva $=2$ ). In first vaccination scheme, detectable anti NDV-HI titer was observed on $16^{\text {th }}$ day of vaccination (Gallivac=3.8, Intervet=4.2 \& Ceva=3.6). All vaccines showed protective anti NDV-HI titer on 32 nd day, post vaccination (Gallivac=5.8, Intervet $=6.2$, Ceva $=5.8)$. In second vaccination scheme, detectable anti NDV-HI titer was achieved on $16^{\text {th }}$ day of post vaccination $(G a l l i v a c=3.8$, Intervet=4.2 \& Ceva=3.6). While on $32^{\text {nd }}$ day vaccination, all vaccines showed protective anti NDV-HI titer (Gallivac=5.4, Intervet=5.6 \& Ceva=5.2). It is concluded that the two-dose vaccination program, with interval of 12 days, is much effective than the 3 -dose vaccination scheme. However, in broilers, anti-NDV antibody titer was induced by all three types of vaccines manufactured by various compa nies.
\end{abstract}

Keywords: Newcastle disease virus, Humoral Response, Haemagglutination inhibition test, Vaccine schedule

Article Info: Received 12 March 2020; Review Completed 24 April 2020; Accepted 29 April 2020; Available online 15 May 2020

Cite this article as:

Mehmood MD, Hashim A, Anwar ul-haq H, Ismail M, Amin F, Hussain S, Humoral response of broilers to live Newcastle Disease virus vaccines manufactured by different companies, Journal of Drug Delivery and Therapeutics. 2020; 10(3):179184 http://dx.doi.org/10.22270/jddt.v10i3.4035

*Address for Correspondence:

Dr. Muhammad Danish Mehmood, PhD, Director Technical's at Ottoman Pharma (Immuno Division), Lahore, Pakistan

\section{INTRODUCTION}

The Newcastle disease (ND), which is also called Ranikhet, is a virus inflicted disease ${ }^{1}$. NDV belongs to genus Avulovirus and family Paramyxoviridae ${ }^{2}$. The signs of this disease are related to nervous, digestive and respiratory systems. Economically there have been many losses due to this disease in poultry industry and many cases have been reported, for many years, from different parts of country too ${ }^{3}$.

Various domestic and wild birds have been affected by this disease. Initially, the disease was observed in England and Indonesia in 1926 but now these viruses have become a worldwide threat ${ }^{4}$. In spite of massive immunization, NDV observed to have been consistently spread over in Pakistan in different commercial poultry like breeding flocks, layers and broilers ${ }^{5}$. Severe problems of the nervous system are characterized by mild signs of air sacculitis, paralysis, and even death of the infected organism by visceral involvement. There are routine NDV vaccination programs and different methods of giving vaccines in forms of intraocular, intranasal, drinking water and aerosol spray ${ }^{6}$. The immune response of broiler chicken is greatly influenced by the chick's ages while vaccinating and during the time of level of antibodies derived maternally, and their response to vicinal antigen is also influenced 7 . There is no satisfactory protection of vaccination used in Pakistan for broiler industry; hence, desired protection may be achieved by few required responses such as antibody or humoral responses ${ }^{5}$. Firstly, the vaccine was used against ND for protection of 
village poultry since fifty years or more ${ }^{8}$. There were many types of vaccines which were developed during that time period. Village poultry was used for testing many but not all vaccines. There is mild conjunctivitis and influenza like symptoms in humans after exposure to the infected but there was no evidence of strong hazards to human health from this ND virus ${ }^{9}$

The ND is still causing major threats to poultry industry in spite of various vaccination schedules provided worldwide by different poultry vaccine manufacture ${ }^{10}$. The effects on chicken are eliminated by different live vaccines and killed by oil-based vaccines which are being used in most countries including Pakistan ${ }^{11}$. Outbreaks are still common in most areas of Pakistan in spite of extensive use of vaccines, causing huge economic losses. Lasota strain, Muktaswer strain, Comrov strain and Hitchner $\mathrm{B}_{1}$ strain are important strains of NDV which are used in Pakistan against NDV for immuno-prophylaxis ${ }^{12}$. The current study is designed to evaluate the comparative humoral response of various sources of live vaccines in healthy NDV susceptible broilers. The objectives of the study are as follows:

- $\quad$ Evaluate the anti NDV-HI antibody effectiveness titers of vaccines manufactured by different sources.

- Compare the different vaccination schedules to get best and optimum protection level in minimum time period.

- To determine the immunogen count and infectivity titer of each NDV vaccine.

- The ultimate goal is, through the results, to provide information to local farmers using the under study vaccines about the proper use and schedule of NDV vaccination.

\section{MATERIALS AND METHODS}

\section{Source of vaccines:}

Three different NDV live vaccines-Gallivac, Intervet and Ceva, were purchased from the sole distributor of each. Each vaccine was packed with dry ice in well-insulated containers, transported to the University of Lahore and stored at the selected temperature, till processed. The experiment of examined studies was revealed in collaboration with the Institute of Molecular biology and Biotechnology, The University of Lahore with Ottoman Pharma, Lahore, Pakistan.

\section{Source and rearing of bird:}

One day old $n=35$ broiler were purchased from the well reputed Big Bird poultry breeders; located at Raiwind road; and were shifted immediately to the clean and fumigated experimental cages. The birds were marked with different dyes, showing that different ones were immunized with different vaccines as shown in Table-3.1. All the birds were offered with feed and water at libitum, under a controlled environment. The humidity and temperature values were checked on regular basis and were noted in the log book as shown in Figure 3.1.

\section{Experimental model:}

\section{Experiment \# 01:}

All the vaccines were opened in the safety cabinet and diluted according to instruction of each manufacturer. The $50 \mu \mathrm{l}$ of diluted vaccinal antigen were assessed for biological titration through haemagglutination assay (HA) test ${ }^{13}$.

\section{Experiment\# 02:}

The birds were divided into three groups with each containing 5 birds marked with different coloring dyes as shown in Table 3.1. The birds in Group A, B and C were immunized with live Gallivac, Intervet and Ceva NDV vaccines respectively at 0,8 and 18 days of age whereas, group D served as negative control as shown in figure 3.2. The blood from each bird of every group was collected on 0 ,

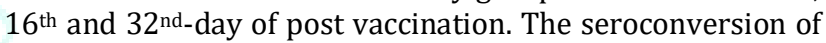
all the birds of the vaccinated group was evaluated by haemagglutination test.

Table 3.1: $1^{\text {st }}$ scheme of immunization

\begin{tabular}{|c|c|c|c|c|c|c|}
\hline \multirow{2}{*}{ Sr. \# } & \multirow{2}{*}{ Groups } & \multirow{2}{*}{ Color } & \multirow{2}{*}{$\begin{array}{c}\text { Injecting } \\
\text { routes }\end{array}$} & & \multicolumn{3}{|c|}{ Types of vaccines } \\
\cline { 4 - 7 } & & & Priming & $\mathbf{1}^{\text {stBooster }}$ & $\mathbf{2}^{\text {nd Booster }}$ \\
\hline 1 & A & Green & Drinking water & Gallivac & Day 8 & Day 18 \\
\hline 2 & B & Yellow & Drinking water & Intervet & Intervet & Gallivac \\
\hline 3 & C & Pink & Drinking water & Ceva & Ceva & Ceva \\
\hline 4 & D & White & Control group & No vaccines & No vaccines & No vaccines \\
\hline
\end{tabular}

\section{Experiment \# 03:}

The birds were divided into three groups each containing 5 birds marked with different coloring dyes as shown in table1. The birds in Group E, F and G were immunized with Gallivac, Intervet and Ceva respectively at $6^{\text {th }}$ and $18^{\text {th }}$ days of age whereas, group D served as negative control as shown in table no 2. The blood from each bird of every group was collected on 0,16 and 32-days post vaccination. The seroconversion of all birds of the vaccinated groups was evaluated by haemagglutination test.

Table 3.2: $2^{\text {nd }}$ scheme immunization schedule

\begin{tabular}{|c|c|c|c|c|c|}
\hline \multirow{2}{*}{ Serial No } & \multirow{2}{*}{ Groups } & \multirow{2}{*}{ Colour } & \multirow{2}{*}{ Injecting routes } & \multicolumn{2}{|c|}{ Types of vaccines } \\
\cline { 4 - 6 } & & & Priming & 1st Booster \\
\cline { 4 - 6 } & & B & Orown & Day $\mathbf{6}$ & Day 18 \\
\hline 1 & F & Blue & Orally & Gallivac & Gallivac \\
\hline 2 & G & Black & Orally & Ceva & Ceva \\
\hline 3 & D & White & Control group & No vaccines & No vaccines \\
\hline 4
\end{tabular}




\section{Collection of Blood Sample:}

$1 \mathrm{cc}$ blood was collected from every bird of each group on 0 , $16^{\text {th }}$ days and $32^{\text {nd }}$ day, post vaccination as shown in Figure 3.3. The serum was separated using centrifuge and sample was run at 3000 RPM for 15 minutes. The supernatant was collected and subjected for haemagglutination inhibition test. $2 \mathrm{ml}$ epindroff tubes were used for packing the serum from each syringe separately, specific codes were used for marking, and then they were frozen at $8^{\circ} \mathrm{C}$ for further processing

Table 1.3: Blood collection and determinations of antibody Titer

\begin{tabular}{|c|c|c|c|c|c|}
\hline Groups & No of Birds & Color & Blood Collected/ml & Position of Injection & Sampling Days \\
\hline A & 5 & Green & $1 \mathrm{ml}$ & Wing vein & $0,16,32$ \\
\hline B & 5 & Yellow & $1 \mathrm{ml}$ & Wing vein & $0,16,32$ \\
\hline C & 5 & Pink & $1 \mathrm{ml}$ & Wing vein & $0,16,32$ \\
\hline D & 5 & White & $1 \mathrm{ml}$ & Wing vein & $0,16,32$ \\
\hline
\end{tabular}

\section{Seroconversion of vaccines:}

Anti NDV antibodies were manufactured at different time interval against specific NDV in 96 well plates as mentioned below:

\section{Haemagglutination assay Test:}

With the help of micropipette, $50 \mu \mathrm{l}$ of normal saline is dispensed in all wells of $1^{\text {st }}$ row of 96 well micro titer plates. $50 \mu \mathrm{l}$ antigens are added in $1^{\text {st }}$ well and 2 fold diluted till $11^{\text {th }}$ well is too. Add $50 \mu \mathrm{l}$ of $1 \%$ washed chicken's RBCs from well 1 to 12 wells. Incubate at $37^{\circ} \mathrm{C}$ for 30 minutes and note the results.

\section{Haemagglutination Inhibition Test:}

With the help of micro pipette, $50 \mu$ l normal saline is dispensed from $1^{\text {st- }} 12^{\text {th }}$ well of 96 well micro titer plates. $1^{\text {st }}$ well is filled to $50 \mu \mathrm{l}$ with serum. Prepare 2 fold serial dilution till the $10^{\text {th }}$ well is reached. Add $50 \mu \mathrm{l} 4 \mathrm{HA}(\mathrm{Ag})$ to $1^{\text {st }}$ well and continue filling till $11^{\text {th }}$ well, is reached by double dilution. It is incubated at $37^{\circ} \mathrm{C}$ for 30 minutes. $50 \mu \mathrm{l}$ of $1 \%$ washed chicken's RBCs is dispensed from $1^{\text {st }}$ to $12^{\text {th }}$ well; the results are analyzed after 20-25 minutes.

\section{Statistical analysis:}

By using mean standard deviation, data is analyzed which is obtained in that study. By using SPSS version 21, subsequently analyze are repeated measures of variables (ANOVA).

\section{RESULTS}

In $1^{\text {st }}$ experiment, $50 \mathrm{ul}$ of each Gallivac, Ceva and Intervet live NDV vaccines showed 64, 64 and 128 haemagglutination titer respectively as shown in Table 4.1 .
Table 2.1: Haemagglutination titer of live Newcastle disease virus vaccines

\begin{tabular}{|c|c|c|}
\hline Vaccines Brand & Dilution & HA titer \\
\hline Gallivac & $50 \mu \mathrm{l}$ & 64 \\
\hline Intervet & $50 \mu \mathrm{l}$ & 128 \\
\hline Ceva & $50 \mu \mathrm{l}$ & 64 \\
\hline
\end{tabular}

In $2^{\text {nd }}$ experiment, the birds $1,2,3,4$ and 5 of group one vaccinated with Gallivac on zero day and $1^{\text {st }}$ booster on $8^{\text {th }}$ day and $2^{\text {nd }}$ booster on 18 day. On zero and $16 \mathrm{DPV}$, there was some detectable anti NDV-HI antibody titers while protective anti NDV-HI antibody titers were achieved on 32 DPV as shown in Table 4.2 and Figure 4.1. Similarly, the birds 1, 2, 3, 4, and 5 of Group 2 vaccinated with intervet on zero day, $1^{\text {st }}$ booster on $8^{\text {th }}$ day and $2^{\text {nd }}$ booster on $18^{\text {th }}$ day. On zero and 16 DPV, some anti NDV-HI antibody titers were detected. While on $32 \mathrm{DPV}$, there was highest anti NDV-HI antibody titer as shown in Table 4.2 and Figure 4.1. Similarly, the birds 1, 2, 3, 4, and 5 of Group 3 vaccinated with Ceva on zero day, $1^{\text {st }}$ booster on $8^{\text {th }}$ day and $2^{\text {nd }}$ booster on 18day. On zero and 16 DPV, showed some anti NDV-HI antibody titers. While on $32 \mathrm{DPV}$, there was highest anti NDV-HI antibody titer as shown in Table 4.2 and Figure 4.1. The birds of group 4 was negative control without giving any vaccination, anti NDV-HI titers were induced but there was not sufficient protective anti NDV-HI antibody titers as shown in Table 4.2 and Figure 4.1.

Table 4.2: Anti NDV-HI titers response to $1^{\text {st }}$ scheme immunization

\begin{tabular}{|l|l|l|l|l|}
\hline Groups & \multirow{2}{*}{ Vaccines } & \multicolumn{3}{|c|}{ HI antibody titer } \\
\cline { 3 - 5 } & & \multicolumn{1}{|c|}{ 0D } & 16D & 32D \\
\hline Group A & Gallivac & $2,2,2,2,2=2.00 \pm 0.00$ & $4,4,3,4,4=3.8 \pm 0.44$ & $6,6,6,6,5=5.80 \pm 0.44$ \\
\hline Group B & Intervet & $2,2,2,2,2=2.00 \pm 0.00$ & $4,4,4,4,5=4.20 \pm 0.44$ & $6,6,6,6,7=6.20 \pm 0.44$ \\
\hline Group C & Ceva & $2,2,2,2,2=2.00 \pm 3.60$ & $4,4,4,3,3=3.60 \pm 0.54$ & $6,6,6,6,7=5.80 \pm 0.44$ \\
\hline Group D & Control group & $2,2,2,2,2=2.00 \pm 0.00$ & $2,1,1,1,1=1.20 \pm 0.44$ & $0,0,0,0,0=0.00 \pm 0.00$ \\
\hline
\end{tabular}




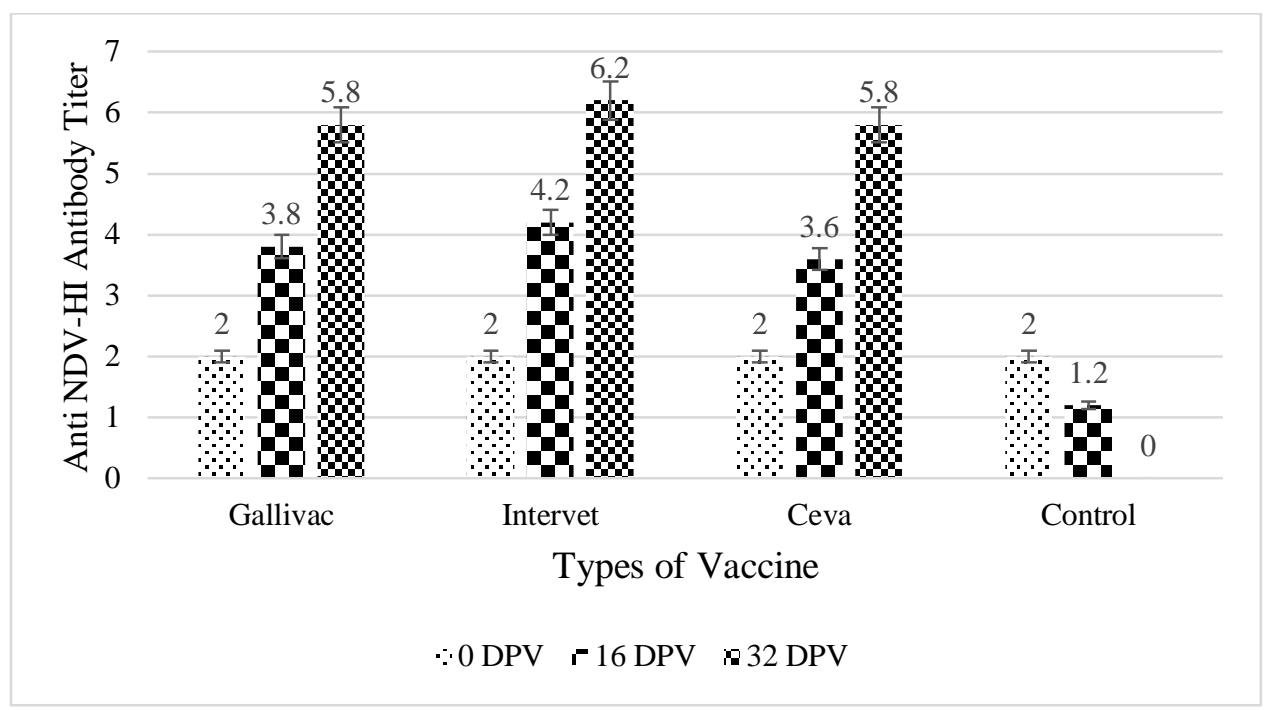

Figure 1.1: Graphical Representation of seroconversion at different time period

In $3^{\text {rd }}$ experiment, the birds $1,2,3,4$ and 5 of group one vaccinated with Gallivac on $6^{\text {th }}$ day and $1^{\text {st }}$ booster on $18^{\text {th }}$ day. On zero and 16 DPV, there was some detectable anti NDV-HI antibody titers while protective anti NDV-HI antibody titers were achieved on $32 \mathrm{DPV}$ as shown in Table 4.3 and Figure 4.2.Similarly, the birds 1, 2, 3, 4, and 5 of Group 2 vaccinated with intervet on $6^{\text {th }}$ day, $1^{\text {st }}$ booster on $18^{\text {th }}$ day. On zero and $16 \mathrm{DPV}$, some anti NDV-HI antibody titers were detected. While on $32 \mathrm{DPV}$, there was highest anti NDV-HI antibody titer as shown in Table 4.3 and Figure 4.2.
Similarly, the birds $1,2,3,4$, and 5 of Group 3 vaccinated with Ceva on $6^{\text {th }}$ day, $1^{\text {st }}$ booster on $18^{\text {th }}$ day. On zero and 16 DPV, showed some anti NDV-HI antibody titers. While on 32 DPV, there was highest anti NDV-HI antibody titer as shown in Table 4.3 and Figure 4.2. The birds of group 4 was negative control without giving any vaccination, anti NDV-HI titers were induced but there was not sufficient protective anti NDV-HI antibody titers as shown in Table 4.3 and Figure 4.2 .

Table 4.3: Anti NDV-HI titers response to $2^{\text {nd }}$ scheme immunization

\begin{tabular}{|l|l|l|l|l|}
\hline Groups & \multirow{2}{*}{ Vaccines } & \multicolumn{3}{|c|}{ HI antibody titer } \\
\cline { 3 - 5 } & & \multicolumn{1}{|c|}{ 0D } & \multicolumn{1}{|c|}{ 16D } & 32D \\
\hline Group E & Gallivac & $2,2,2,2,2=2.00 \pm 0.00$ & $4,4,3,4,4=3.8 \pm 0.44$ & $5,5,5,6,6=5.40 \pm 0.54$ \\
\hline Group F & Intervet & $2,2,2,2,2=2.00 \pm 0.00$ & $4,4,4,4,5=4.20 \pm 0.44$ & $6,5,5,6,6=5.60 \pm 0.54$ \\
\hline Group G & Ceva & $2,2,2,2,2=2.00 \pm 0.00$ & $4,4,4,3,3=3.60 \pm 0.54$ & $5,5,5,6,5=5.20 \pm 0.44$ \\
\hline Group D & Control group & $2,2,2,2,2=2.00 \pm 0.00$ & $2,1,1,1,1=1.20 \pm 0.44$ & $0,0,0,0,0=0.00 \pm 0.0$ \\
\hline
\end{tabular}

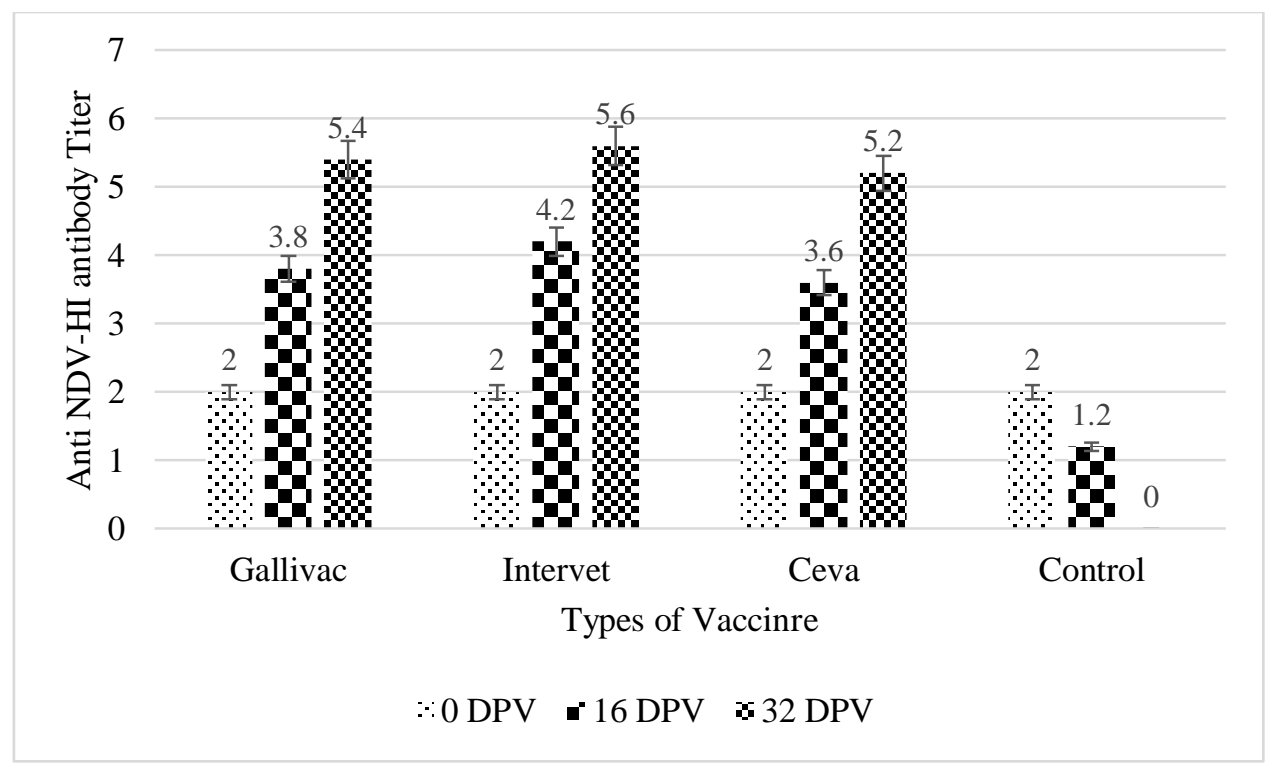

Figure 4.2: Graphical Representation of seroconversion at different time period 


\section{DISSCUSION}

Newcastle Disease (ND) is the fourth most dangerous viral disease affecting the poultry industry, all over the world. A large number of countries are affected by many animal diseases like Bovine tuberculosis, rabies and Newcastle disease, which were considered to be the most widespread animal diseases from 2006 to 2009. The mesogenic and lentigenic strains of NDV are used for Immunization in layer and broiler flocks. Newcastle disease was identified firstly in Island of Java and England in 1926. On global scale, presently this virus is responsible for epizootic events may cause epidemics.

Live vaccines instead of killed vaccines are preferred because live vaccines can be prepared on large scale for having low immunogen count, particularly having one that is easily administered, is low cost to get cell-mediated and provide humoral and mucosal surface's long lasting immunity in a single dose. There are some disadvantages in the use of such, for these are less stable, allergen and have potential to revert their virulent forms, while killed vaccines are of advantage in these departments, being more stable and being noninfectious. The disadvantages however, include short halflife, need adjuvants, require multiple doses and need boosters ${ }^{14}$.

Newcastle Disease (ND) is controlled by intensive use of vaccination, but natural out breaks are reported in many vaccinated flocks. According to Sarcheshmei vaccine, failure in such cases is associated with vaccination program, type of vaccines, homology of vaccinal and wild type strain, vaccination equipment, maternal antibody and the type of birds ${ }^{15}$. Virulence of wild type strain could be evaluated through intravenous pathogenicity index (IVPI), mean death time (MDT) and intracerebral pathogenicity index (ICPI) however, homology between two types can be established by virus neutralization test 16 .

Haemagglutination test is for confirmatory diagnosis and for provision of specific, sensitive, more accurate and rapid tests for titration of haemagglutinating viruses ${ }^{17}$. Our studies revealed that Initial HI-antibody titer in both experiments are same at zero day, while, they were detected on $16^{\text {th }}$ day post vaccination. Gallivac, Intervet and Ceva showed almost similar anti NDV-HI antibody titers on 16D post vaccination in both experiments, while Intervet showed comparatively high HI-antibody titer $(4.2,6.2)$ than Gallivac $(3.8,5.8)$ and Ceva $(3.6,5.8)$ in both experiments on $16^{\text {th }}$ and $32^{\text {nd }}$ post vaccination. There was no significant difference between Gallivac and Ceva on $16 \mathrm{D}$ and $32 \mathrm{D}$ post vaccination. The NDV live vaccine immunization in broilers primed on 0 day and boosted on $8^{\text {th }}$ day of age showed detectable anti NDV-HI antibody titers (> 3.6) for all the three vaccines at $16^{\text {th }}$ day post vaccination. However, protective anti NDV-HI titers $(>$ 5.8) were achieved on $32^{\text {nd }}$ day post vaccination, after $2^{\text {nd }}$ booster dose given on 18 day of age. It was also observed that birds immunized with Intervet vaccines showed comparatively higher antibody response (6.2) as to that of Ceva (5.8) vaccine and Gallivac (5.8).

The results of the current study are in line with the observations of Makoui, who immunized the broilers with different live ND vaccines on $8^{\text {th }}$ day, $22^{\text {nd }}$ day and $36^{\text {th }}$ day by drinking water whereas the HI test revealed that in titration there is significant difference between all the vaccines ${ }^{18}$. Bwala also conducted a study on different NDV vaccines and determined that there was no significant difference in protection level of different vaccines ${ }^{19}$. The writer Muir, 2000 also proved that antibody titer was enhanced by booster doses after priming, while there was no significant enhance the high antibody titer after priming ${ }^{20}$.

ISSN: 2250-1177
The NDV live vaccine immunization in broilers primed on $6^{\text {th }}$ day showed detectable anti NDV-HI antibody titers (> 3.6) for all the three vaccines on $16^{\text {th }}$ day, post vaccination. However, protective anti NDV-HI titers $(>5.2)$ were achieved on $32^{\text {nd }}$ day post vaccination after $1^{\text {st }}$ booster dose given on $18^{\text {th }}$ day of age. It was also observed that the birds immunized with Intervet vaccines showed a comparatively higher antibody response (5.6) as to that of Ceva (5.2) vaccine and Gallivac (5.4). Our study was in agreement with Xiao, who investigated about efficacy of commercially available live NDV vaccines and evaluated 2 different vaccination schemes on 2 different days. There was no significant difference in $\mathrm{HI}$ antibody titer between the Lasota vaccines alone. In the $2^{\text {nd }}$ scheme, Lasota was provided with Mukteshwer, causing a significant difference between protective index of scheme $B$ and scheme $A^{21}$.

The observation of Giambrone was also in line with our study who evaluated ND vaccination programs and has examined that there were highest NDV HI titers and in birds, there was greatest resistance to the challenge ${ }^{22}$. These birds were firstly immunized with live vaccines on $1^{\text {st }}$ day by coarse spray and then re-immunized with same vaccines on day 14. There was an increase in the antibody titer after priming. In vaccinated birds, there was a decrease in the HI antibody titer after a challenge whereas in non-vaccinated birds, there was an increased $\mathrm{HI}$ antibody titer. These findings were approved by $\mathrm{Ge}$, who determined that neutralization of viruses by circulating antibodies, was involved in decreasing antibody titer ${ }^{23}$.

The experiment was carried on 90 broilers with different vaccination schedules and divided these birds into four groups. Three were immunized with all vaccines on different days orally and with aerosol spray but the fourth group was taken as negative control. After performing HI, the antibody titer was determined after collecting blood samples on $1^{\text {st }}$ $15^{\text {th }}, 28^{\text {th }}$ and $43^{\text {rd }}$ day, post vaccination and their results showed that in both vaccination schedules, all vaccines showed detectable antibodies and there was no comparative difference between the antibody titers of all three vaccines. Even though during their study period, vaccination days were different, their HI results still correlated to our study.

\section{CONCLUSION}

Different vaccinations schemes in broilers are being trialed to get maximum protection against velogenic strain of new castle disease virus. However, it would not be possible for scientists to set a standard schedule for NDV immunization due to randomization in maternal antibody titer. The results of current study would help the farmers to establish twodose vaccination program with interval of 12 days is much effective to that of 3-dose vaccination scheme. However, all three types of vaccines manufactured by different companies are capable of inducing anti-NDV antibody titer in broilers.

\section{REFERENCES}

1. Leighton \& Heckert. Newcastle Disease and related avian Paramyxoviruses. Infectious diseases of wild birds. 2007; 8(2):3-16.

2. Al-Garib. Review of Newcastle disease virus with particular references to immunity and vaccination. World's poultry science journal. 2003; 59(2):185-200.

3. Marangon \& Busani. The use of vaccination in poultry production. Revue Scientifique et Technique-Office International des Epizooties. 2007; 26(1):265-74.

4. Lancaster. A history of Newcastle disease with comments on its economic effects. World's Poultry Science Journal. 1976; 32(2):167-75.

5. Akhtar, \& Zahid. Risk indicators for Newcastle disease outbreaks in broiler flocks in Pakistan. Preventive Veterinary Medicine. 1995; 22(1):61-69. 
6. Wuchter \& Cornelia. Archaeal nitrification in the ocean. Proceedings of the National Academy of Sciences. 2006; 103(33):12317-22.

7. Hussien. Comparative studies on the effect of aflatoxins types on the immunization of one-day-old broiler chicks simultaneously vaccinated against newcastle disease and infectious bronchitis disease. Life Science Journa. 2012; 9(4):3774-82.

8. Bell. A comparison of the different vaccines available for the control of Newcastle disease in village chicken. ACIAR proceedings. 1998; 24(3):50-62.

9. Swayne, D \& King, D. Avian influenza and Newcastle disease. Journal of the American Veterinary Medical Association. 2003; 222(11):1534-40.

10. Kapczynski, D.C.A \& Miller, P. Immune responses of poultry to Newcastle disease virus. Developmental \& Comparative Immunology. 2013; 41(3):447-53.

11. Hilton, L..A.G.B. \& Lowenthal. J. The emerging role of avian cytokines as immunotherapeutics and vaccine adjuvants. Veterinary Immunology and Immunopatholog. 2002; 85(3):119-28.

12. Munir \& Tajammal. The current status of process analytical technologies in the dairy industry. Trends in Food Science \& Technology. 2015; 43(2):205-18.

13. Allan $\mathrm{WH}$, et al. Newcastle disease vaccines, their production and use. FAO animal production and health series. 1978; 5762.

14. Banu. Determination of immune response of Newcastle disease virus vaccines in layer chicken. Journal of the Bangladesh Agricultural University. 2009; 329-34.

15. Sarcheshmei. Comparative evaluation of the protective efficacy of different vaccination programs against a virulent field strain of the Newcastle Disease virus in broilers. Brazilian Journal of Poultry Science. 2016; 44(8):363-70.

16. Putri \& Dwi Desmiyeni. Pathotypic characterization of Newcastle disease virus isolated from vaccinated chicken in West Java, Indonesia. Veterinary world. 2017; 10(4):438-44.

17. Pansota \& Masood, F. Use of hyperimmune serum for passive immunization of chicks experimentally infected with Newcastle disease virus. Pak. J. Agri. Science. 2013; 50(2):27988.

18. Makoui, M.H. \& Feizi, A. Efficacy of different live Newcastle disease vaccines in broiler farms. European Journal of Zoological Research. 2014; 3(1):81-8.

19. Bwala \& Garba, D. Efficacy of a genotype 2 Newcastle disease vaccine (Avinew $®$ ) against challenge with highly virulent genotypes $5 \mathrm{~d}$ and $3 \mathrm{~d}$. Journal of the South African Veterinary Association. 2009; 80(3):174-78.

20. Muir \& Bryden. Immunity, vaccination and the avian intestinal tract. Journal of Developmental \& Comparative Immunology. 2000; 24(2-3):325-42.

21. Xiao, B., \& Hu. Enhancement of immune responses to Newcastle disease vaccine by a supplement of extract of Momordica cochinchinensis (Lour.) Spring. Seeds. Journal of Poultry science. 2009; 2293-2297.

22. Giambrone \& Clay. Evaluation of broiler breeder pullet vaccination programs for preventing clinical reovirus infections in the progeny. Journal of Poultry science. 1986; 65(3):457-61.

23. Ge, J. Newcastle disease virus-vectored rabies vaccine is safe, highly immunogenic, and provides long-lasting protection in dogs and cats. Journal of virology. 2011; 85(16):8241-52. 